\title{
Some Animadversions upon a Review of the CeEct Edition of De Mille's A Strange Manuscript
}

\author{
M.G. Parks
}

It is generally agreed, and rightly so, that an author should hold his peace when one of his offspring happens to receive a negative review, even if that review is manifestly unfair as well as negative. When a negative review, however, wrongly attributes errors and deficiencies not only to the author's work but also to others, then a rebuttal may serve a useful purpose. Such is the case with a review of one of the volumes in the Centre for Editing Early Canadian Texts series, the edition of James De Mille's $A$ Strange Manuscript Found in a Copper Cylinder. The review of that edition by Professor R.G. Moyles in the Papers of the Bibliographical Society of Canada, Xxvi, (I987), pp. I67-69, castigates the Centre for its 'poor judgement' in selecting this novel for the series and for spending 'an inordinate amount of public money ... to achieve such unsatisfactory results.' This severe criticism is based, however, upon a highly questionable critique of the De Mille volume. For this reason I offer the following comments on Professor Moyles' review.

(I) It is simply not true to say that what the reviewer considers to be 'meagre textual results' - that is, the results of the discovery that the copytext of A Strange Manuscript did not need major emendation - 'might have been predicted very easily in advance by the very nature of the text.' The state of the first printed version of the novel, the serial that appeared in Harper's Weekly from January to May, r888, could not have been 'predicted very easily in advance.' One might say, of course, that because Harper's in the I880 was a leading publisher with high standards of production, the text of a novel in Harper's Weekly should therefore be relatively free of errors; but the reviewer must know that an editor cannot allow such assumptions, really mere guesswork, to determine whether or not a particular work should be included in a series of scholarly editions. The state of a text can be known precisely only after what the reviewer admits was a 'diligent collation' has been completed - and that is exactly what happened with the copy-text of $A$ Strange Manuscript.

(2) It is perhaps regrettable that the editing of this particular text did not produce the excitement that the reviewer sees as arising from an abun- 
dance of 'textual cruxes;' but the textual apparatus, 'dull' though it may be when measured on his scale of excitement, is not really so utterly devoid of 'textual cruxes' and 'matters to engage the editor's skill' as he declares. At least a few teasing puzzles turned up to alleviate editorial tedium, publisher's errors such as 'viniformis' for 'reniformis,' 'Arobur' for 'a Robur,' 'Eolithic' for 'Oolitic,' 'authors' for 'Athons.' This last error in the copytext and in all other printed versions, by the way, had already led one blameless literary critic to expound upon the place of 'authors' in the Kosekin social scale and to attribute to De Mille an ironic comment on the place of writers in Western society; the correction (Athons) eliminates the possibility of such mistaken interpretation.

Even if the reviewer were accurate in calling the CEECT text 'a virtual reprint' of the text that appeared in Harper's Weekly, it should be remembered that the serial text is not the one available to readers in the only other easily accessible printing, that of the New Canadian Library edition of r969. The first book edition, of which the NCL edition is indeed 'a virtual reprint,' is not as good a text as the reviewer seems to think when he calls the CEECT text 'little superior' to the NCL text; as is made clear in the Editor's Introduction, 'the book [edition] introduces numerous emendations and creates a considerable number of errors.' Since many of its emendations are misguided, it is significantly inferior to the serial text.

(3) The reviewer's assumption that the editor, 'facing few textual challenges, has tried to bolster what was promising to be a rather empty textual apparatus,' is simply not true. Nor is it true that 'we must assume that, given the usual purpose of such a list [of emendations], these [the editor's] are considered to be substantive changes.' The editor listed all emendations to the copy-text, and he did not distinguish between 'accidentals' and 'substantives;' although CEECT was well aware of W.W. Greg's separation of the two kinds of emendations, it did not choose to follow his definition of 'such a list,' and so the list under criticism here was never intended to consist of 'substantive' emendations only. The reviewer's error about this point seems odd, since the inclusiveness of the list is clearly stated in the first sentence of the headnote to 'Emendations to Copy-text' on p. 3I9. Did he not read the headnote? The editor, moreover, was fully aware that the many corrections of 'every one' to 'everyone,' 'any one' to 'anyone' and 'some one' to 'someone' are by no means substantive emendations. Therefore, when the reviewer 'wonders if such an apparatus can be taken seriously' because he ascribes to the editor (whom, strangely enough, he later calls 'no doubt ... a fine textual critic') such puerile confusion about substantives, one can conclude only that the reviewer has missed the point entirely.

(4) The concluding sentence of the third paragraph is seriously mislead- 
ing. The only 'silent' emendations made to the copy-text are specified in the Editor's Introduction, p. lii, and consist of chapter numbers, capitalization at the beginning of chapters, and punctuation marks incorrectly printed in italics - and, of course, none of them is substantive. The example offered by the reviewer of another silent emendation not covered by the Introduction, the insertion of a comma after 'England' in the sentence, 'In England, we make tin cans for everything,' is not an editorial emendation at all, and it definitely does not, as the reviewer hints, represent what may be other 'silent' emendations 'more substantive than those listed.' In fact, this particular comma is a gremlin that originated as a spot on the plates and was read as a comma in the blues. That error is certainly embarrassing when one considers how painstakingly everyone concerned with this text worked for absolute accuracy. It is not, however, the result of editorial intention.

(5) The reviewer's comments on the editor's use of De Mille's 'Ashdod Webster' manuscript are essentially baseless and perverse. The 'speculative evidence' drawn from this handwritten manuscript of a novel De Mille prepared for publication was not 'used to support the Harper's Weekly text' in the sense of 'defend[ing] the choice of copy-text.' As the reviewer says, there was no need to defend that choice. The 'Ashdod Webster' manuscript was used to offer evidence that various elements in the copy-text of A Strange Manuscript are matched by De Mille's actual practice as revealed by the manuscript. Not the choice of copy-text but the relation to De Mille's known practices, especially in spelling and punctuation, was the issue here. After all, the serial version of A Strange Manuscript might have been a heavily edited version of De Mille's manuscript, for De Mille was not there to assert his rights as author. A comparison of the copy-text and the 'Ashdod Webster' manuscript served the useful purpose of confirming the nature of the copy-text rather than defending its choice. Indeed, since the manuscript of $A$ Strange Manuscript is missing, it would have been irresponsible of the editor to pay no attention to this excellent example of a De Mille manuscript ready for the printer.

(6) The fifth paragraph of the review expands upon the charges levelled in the second paragraph. 'In this case an editorial mountain has been made out of a textual molehill,' the reviewer complains, and repeats his previous ill-advised assertion that the state of the copy-text 'could have been predicted with little difficulty.' Here also, as before, the reviewer disregards, or is unaware of, the many differences between the serial edition of the novel and the book edition used for the New Canadian Library reprinting of I969, which he thinks is quite satisfactory in spite of its many errors. While it might fairly be said that the serial edition of the novel, as became clear after exhaustive collations, required no extensive emendation, the 
reviewer should have noted what the editor says about the text of the book edition - that Harper's created many unwarranted changes, some of them outright errors, in the process of setting the book edition from the text of the serial. Since the serial is generally a much better text than the book edition, an edition based upon the serial is bound to offer a more satisfactory text than any reprinting of the book edition.

(7) The final paragraph of the review castigates CEECT for its poor judgement in the choice of $A$ Strange Manuscript as part of its series of scholarly editions. Since the castigation is based upon the invalid premise that it could have been known beforehand that the copy-text would not need extensive critical editing, and upon the conviction that the text of the serial edition was not much superior to that of the book edition, the reviewer's conclusions of 'unsatisfactory results' that waste 'an inordinate amount of public money' are also invalid.

Finally, it is disturbing that the review concentrates entirely upon the text of this edition. Except for one offhand reference to the 'excellent evaluative introduction to the text,' the reviewer ignores the other major parts of the edition, in particular the extensive introduction on the composition and history of the book and the explanatory notes; these, according to other reviewers, make a significant contribution to scholarship. This reviewer, however, was not to be diverted from his unremitting focus on the text alone; he was convinced, it appears, that it actually deserves all the ill-tempered and even patronizing criticism he looses upon it. When much of that criticism, however, is shown to be either baseless or false, the hostility and thinly veiled condescension are left with little substance to support them. 